Sharif University of Technology
Scientia Iranica
Transactions E: Industrial Engineering
http://scientiairanica.sharif.edu

\title{
Modeling and analyzing pricing and inventory problem in a closed-loop supply chain with return policy and multiple manufacturers and multiple sales channels using game theory
}

\author{
L. Nazari ${ }^{a, *}$, M. Seifbarghy ${ }^{\mathrm{b}}$, and M. Setak \\ a. Department of Industrial Engineering, Science and Research Branch, Islamic Azad University, Tehran, Iran. \\ b. Department of Industrial Engineering, Alzahra University, Tehran, Iran. \\ c. Department of Industrial Engineering, K.N. Toosi University of Technology, Tehran, Iran.
}

Received 29 June 2015; received in revised form 21 November 2016; accepted 17 June 2017

\author{
KEYWORDS \\ Pricing; \\ Inventory; \\ Closed loop supply \\ chain; \\ Game theory; \\ Substitutable product; \\ Repair center.
}

\begin{abstract}
This paper focuses on determining ordering and pricing policies in a singleperiod closed-loop supply chain. The assumed supply chain includes a number of manufacturers who provide their different, yet substitutable, products for their customers via a common retailer; however, manufacturers can have their own internet-based sales channels in order to provide products for the customers. The customers can return products if they are not satisfied with them. The returned products are collected in a repair center, repaired, and sold as second-hand products through the retailer's channel or through an internet-based sale channel. The customer demand is assumed to be stochastic. This study aims to determine the optimum prices for the internet-based and retailer's sales channels for the initial and second-hand products. It also tries to determine the optimal values of retailer order and production rates of manufacturers and repair centers. Three types of game strategies for the supply chain, including Nash, Stackelberg game with a retailer as the leader, and Stackelberg game with manufacturers and repair center as the leaders, are studied in a decentralized condition. The analytical equilibrium solutions, equations, and constraints are extracted for these strategies. Finally, the effect of variations in key parameter is investigated.
\end{abstract}

(C) 2018 Sharif University of Technology. All rights reserved.

\section{Introduction}

The widespread use of internet has convinced many manufacturers, such as Panasonic, Kodak, and Apple, to exploit internet-based sales channels. Today,

\footnotetext{
*. Corresponding author. Tel.: +098 2433753264;

Fax: +098 2433753264

E-mail addresses: nazari-l@abhariau.ac.ir (L. Nazari);

m.seifbarghy@alzahra.ac.ir (M. Seifbarghy);

setak@kntu.ac.it (M. Setak)
}

doi: $10.24200 /$ sci. 2017.4459 supply chains face competition among sales channels as well as competition among brands. Gan et al. (2017) [1] showed that implementing a separate channel, such as the internet channel, could improve the total supply chain's profit, as compared to the singlechannel approach. Recently, considerable researches have been conducted on the impact of internet-based sales channels and their pricing strategies. Chiang et al. (2003) [2] pointed out that generating internetbased sales channels was valuable for manufacturers and retailers leading to increased profitability. Since price is a prominent factor affecting product demand, 
its optimization significantly affects acquiring a desirable market share. Kumar and Ruan (2006) [3] demonstrated that manufacturers and retailers' decisions on pricing were influenced by customers' loyalty to brand and sales channels. Dai et al. (2005) [4] investigated optimum pricing strategies while retailers were competing for attracting more customers. Kurata et al. (2007) [5] obtained the optimal pricing policy in the presence of competition between brands and sales channels.

The optimal ordering policy is another crucial factor that affects the profit and cost of a supply chain as well as the pricing strategy. This factor is the optimal value of order. Chung et al. (2014) [6] examined pricing and inventory policies in a supply chain with multiple suppliers using four strategies and game theory.

The importance of the environment protection has necessitated the decrease of exploited raw materials as well as increasing product recycling. Therefore, a Closed-Loop Supply Chain (CLSC) has attracted great attention in recent years. In Europe, around 5.5 to 6.5 Million tons of electrical materials waste are produced annually and are anticipated to increase $16-28 \%$ annually [7]. Remanufacturing is a recovery process that transforms a used product (second-hand product) into a "like-new" product [1]. Gan et al. (2017) [1] developed a pricing decision model for short life-cycle products in a closed-loop supply chain that consists of the manufacturer, retailer, and collector. In this study, the new product is sold via traditional retail stores, and the remanufactured product is sold via the manufacturer's direct channel. Huang et al. (2013) [8] determined the optimal pricing and recycling strategies in a CLSC with two recycling centers using game theory. Maiti and Giri (2015) [9] employed game theory to determine an optimal pricing strategy in a CLSC. Ramezani et al. (2014) [10] investigated the financial perspective in a given closed-loop financial chain. Kaya and Urek (2016) [11] analyzed a network design problem for a closed-loop supply chain and presented a mixed integer nonlinear facility locationinventory-pricing model to decide on the optimal locations of the facilities, inventory amounts, prices for new products, and incentive values for the collection of right amount of used products in order to maximize the total supply chain profit.

Game theory is a popular technique for competitive problems due to its simplicity and logical procedure. Numerous studies have been carried out in recent years on determining competitive parameters including price, service level, and the order size using game theory. Dan et al. (2012) [12] utilized game theory to determine optimal pricing policies and an optimal service level in a supply chain consisting of a traditional retailer and two manufacturers who use internet for sell- ing their products. Chen et al. (2013) [13] determined a pricing policy for a supply chain, including a retailer and two manufacturers, in a decentralized condition using game theory. In this research, it was assumed that one of these manufacturers had its own internetbased distribution channel. Zhao et al. (2013) [14] proposed a method based on game theory through which optimal pricing and distribution policies were determined in a supply chain including two suppliers and a common retailer. Furthermore, the parameters are assumed to be vague. In Tiaojun and Tiantian study (2013), [15] optimal decisions associated with price and service levels were made using game theory in a supply chain which employed a Vendor Management Inventory (VMI) policy. In another study, Chung et al. (2014) [6] utilized game theory in order to determine the optimal pricing and coordination policies in a supply chain. The investigated supply chain included a traditional retailer and a number of manufacturers who utilized internet sales channels. Optimal pricing policies were obtained for a supply chain with two manufacturers who gave two substitutable products and a common retailer using game theory by Zhao et al. (2014) [16]. In this research, different competitive policies together with different power structures were considered for each member of the chain. The game theory was also used by Zhao and Wang (2015) [17] in a fuzzy environment in order to determine pricing and service levels in a supply chain with one supplier and two retailers. Maiti and Giri (2017) [18] studied a two-period supply chain model which is comprised of one manufacturer and one retailer involved in trading a single product. They assumed that the manufacturer acts as the Stackelberg leader and declares wholesale price(s) to the retailer who follows the manufacturer's decision and sets his selling prices for two consecutive periods. Zhou et al. (2017) [19] investigated a threeechelon manufacturing and remanufacturing ClosedLoop Supply Chain (CLSC) constituting a retailer, a manufacturer, and a supplier to maintain inventory service levels.

Seung and Byung (2016) [20] determined the sales prices of new and refurbished items in a three-echelon closed-loop supply chain consisting of a manufacturer, a seller, and a refurbisher based on a comprehensive model.

In this paper, a CLSC including a number of manufacturers with their own internet-based sales channels and a traditional retailer who competes with the internet-based sales channels can be considered in the forward supply chain. In the backward chain, a repair center with its internet channel is considered. Due to the competitive structure of the problem, game theory is used for the decentralized condition of the supply chain. Nash and Stackelberg games are used for determining optimal pricing and ordering policies. 
Two conditions are considered when using Stackelberg games: retailer leadership and manufacturer and repair center leadership.

The problem is to find the optimal pricing policy and determine optimal order sizes in single-period as manufacturers produce different substitutable products. A manufacturer sells its products to a retailer at a wholesale price, and the retailer provides the product for the customer as shown in Figure 1. Simultaneously, the manufacturer may give his products via its internetbased sale channel (if there is any). In the given supply chain, the competition is between brands and distribution channels. Customers cannot touch or feel a product before they purchase online. This leads to much higher rates of customer returns in the online channel, which in turn leads to significant costs for retailer or manufacturer [21]; then, it is supposed herein that customers can return purchased products before use (for an internet-based sales channel). It is also supposed that customers may return products after use (for both channels). Products which are not given at delivery time are returned to the corresponding manufacturer through the same service by which it was sent (such as post) without any charge for customers. The return expenses are paid by the manufacturer. It is assumed that a portion of purchased products is returned, repaired, and resold as second-hand products. These returned products are purchased from customers at the price which is the average of initial products price and are sent to a repair center. Afterwards, purchased products are separated and repaired so that they can be sold as second-hand products. An internet-based sale channel (if there is any) and the retailer are responsible for selling the second-hand products. Demand is assumed to be stochastic for all products depending on price, a retailer's channel service level, the competitor's price, and customers' loyalty to the product or sales channel. Order size is assumed stochastic depending on demand and risk factor of customers. The generic structure of the CLSC is depicted in Figure 1. The given structure, composed of the manufacturers with their own internet-based sales channel, retailers, and repair centers, is more realistic and applicable to the real-world conditions.

Therefore, the contribution of this research is solving the investigated problem of inventory and pricing for the given CLSC.

The rest of this paper is organized as follows. In Section 2, notations are given. Section 3 presents problem formulation. Section 4 examines the model in a decentralized condition based on Nash game and Stackelberg game policies when either a retailer is the leader or manufacturers with repair center are the leaders. Section 5 gives a numerical example to analyze the problem. The effects of parameters on profit and order size are examined in Section 6. Finally, Section 7 gives conclusions and future research ideas.

\section{Notation}

Subscripts $r$ and $d$ respectively represent a retailer's and internet-based sales channels; $r p$ represents repaired products (second-hand products), while $r c$ refers to used products which are returned to repair centers by the customer.

$P_{i j} \quad$ The price of product $i$ which is sold in channel $j(j=r, d ; i=1,2, \ldots, m, r p)$;

Prc Average cost of purchasing returned second-hand products from customers;

$W_{i} \quad$ Wholesale price of product $i$ $(i=1,2, \ldots, m, r p)$;

$\gamma_{i} \quad$ A parameter which shows sensitivity to service level of the $i$ th product in a retailer's channel. It means that, in case of one unit increase (decrease) in a retailer's service level for the $i$ th product, the demand of the product in a retailer's channel increases (decreases) $\gamma_{i}$ units $(i=1,2, \ldots, m, r p)$;

$\gamma_{i i} \quad$ A parameter which denotes sensitivity to the service level of the $i$ th product in an internet-based sales channel. It means that, in case of one unit increase (decrease) in the retailer's service level for the $i$ th product, the demand of the product in an internet-based channel decreases (increases) $\gamma_{i i}$ units $(i=1,2, \ldots, m, r p)$;

$\gamma_{i j} \quad$ A parameter which demonstrates sensitivity of the $i$ th product demand to service level of the $j$ th product in internet-based and a retailer's sales channels. It means that, in case of one unit increase (decrease) in the service level for the $j$ th product, the demand of the $i$ th product in a retailer's and internet-based sales channels decreases (increases) $\gamma_{i j}$ units $(i, j=1,2, \ldots, m, r p)$;

$v_{i} \quad$ Service level offered for the $i$ th product in a retailer's channel $(i=1,2, \ldots, m, r p)$;

$\eta \quad$ Service cost factor for retailer $(\eta>0)$, and $1 / \eta$ represents efficiency of investment in the service $(i=1,2, \ldots, m, r p)$;

$c\left(v_{i}\right) \quad$ Cost function of offered service $\left(v_{i}\right)$ for the $i$ th product in a retailer's channel $(i=1,2, \ldots, m, r p)$; 
$\beta_{i j r} \quad$ Inter-brand price sensitivity which demonstrates sensitivity of the $i$ th product demand in a retailer's channel to price of the $j$ th product in a retailer's sales channels. It means that if the price of the $j$ th product in a retailer's channel increases (decreases) by one unit, the demand of the $i$ th product in retailers' channels increases (decreases) by $\beta_{i j r}$ units $(i \neq j)$, $(i, j=1,2, \ldots, m, r p)$;

$\beta_{i j d} \quad$ Inter-brand-inter-channel sensitivity (inter-channel price sensitivity if $i=j$ ) which demonstrates sensitivity of the $i$ th product demand in the retailer's channels to price of the $j$ th product in an internet-based sales channel. It means that if the price of the $j$ th product in the internet-based sales channel increases (decreases) one unit, the demand of the $i$ th product in a retailer's channel increases (decreases) $\beta_{i j d}$ units $(i \neq j),(i, j=1,2, \ldots, m, r p)$;

$\theta_{i j r} \quad$ Inter-brand-inter-channel sensitivity (inter-channel price sensitivity if $i=j$ ) which demonstrates sensitivity of the $i$ th product demand in an internet-based channel to price of the $j$ th product in a retailer's channel. It means that if the price of the $j$ th product in a retailer's channel increases (decreases) one unit, the demand of the $i$ th product in an internet-based channel increases (decreases) $\theta_{i j r}$ units $(i \neq j),(i, j=1,2, \ldots, m, r p)$;

$\theta_{i j d} \quad$ Inter-brand price sensitivity which demonstrates sensitivity of the $i$ th product demand in an internet-based sales channel to the price of the $j$ th product in an internet-based sales channel. It means that if the price of the $j$ th product in an internet-based channel increases (decreases) by one unit, the demand of the $i$ th product in an internet-based channel increases (decreases) by $\theta_{i j d}$ units $(i \neq j)$, $(i, j=1,2, \ldots, m, r p)$;

$b_{i j} \quad$ Self-sensitivity to the $i$ th product price in the $j$ th channel. It means that if the price of the $i$ th product in the $j$ th channel increases (decreases) one unit, demand in the same channel decreases (increases) $b_{i j}$ units. $(i=1,2, . ., m, r p$, $j=r, d)\left(b_{i j}>0\right)$;
$d_{i j} \quad$ Average expected demand for the $i$ th product in the $j$ th channel $(i=1,2, . ., m, r p, j=r, d)$;
$D_{i j} \quad$ Stochastic value of $d_{i j}$;
drc Demand function for second-hand products used by customers;
Drc $\quad$ Stochastic value of $d r c$;
$a_{i j} \quad$ Potential demand of product $i$ in the $j$ th sales channel $(i=1,2, . ., m, r p$, $j=r, d)$;

$a$

Total market potential in both the retailer's and internet-based channels;

$\propto_{i j} \quad$ The percentage of whole market potential $(a)$ dedicated to the $i$ th product in the $j$ th channel $(i=1,2, . ., m, r p, j=r, d)$;

$\varepsilon_{i j} \quad$ Random variable with $\mathrm{CDF} F_{i j}($.$) at$ the $\left[\varepsilon_{i j}, \bar{\varepsilon}_{i j}\right]$ interval, assuming that $E\left(\varepsilon_{i j}\right)=1(i=1,2, . ., m, r p, j=r, d)$;

$q_{i j} \quad$ The order amount of product $i$ in the $j$ th channel $(i=1,2, . ., m, r p, j=r, d)$;

$Y_{i j} \quad$ The number of deliverable products for $q_{i j}$ order $(i=1,2, . ., m, r p, j=r, d)$;

$y_{i j} \quad$ Random variable with $\mathrm{CDF} F_{i j}($.$) at$ the $\left[y_{i j}, \bar{y}_{i j}\right]$ interval, assuming that $E\left(y_{i j}\right)=1(i=1,2, . ., m, r p, j=r, d)$;

$s_{i j} \quad$ The value of unsold surplus of the $i$ th product in the $j$ th channel at the end of period $(i=1,2, . ., m, r p, j=r, d)$;

$t_{i j} \quad$ The cost of shortage in product $i$ in each channel $(i=1,2, . ., m, r p$, $j=r, d)$;

$m_{i j} \quad$ The value of surplus of unallocated products in the $j$ th channel when the allocated capacity is more than $q_{i j}$ order at the end of period $(i=1,2, . ., m, r p, j=r, d)$;

$c p_{i} \quad$ Production cost of each unit of product $i(i=1,2, \ldots, m)$;

$c d d_{i} \quad$ Cost of distributing product $i$ in an internet-based sales channel $(i=1,2, \ldots, m, r p)$;

$c d r_{i} \quad$ Cost of distributing product $i$ in a retailer's sales channel $(i=1,2, \ldots, m, r p)$;

crp Repair cost of each unit of second-hand products;

$c r_{i} \quad$ Return cost of each product $(i=1,2, \ldots, m, r p, r c)$;

$c c \quad$ The cost of classifying returned products for repair purposes; 
$z_{i j} \quad$ Risk factor for $D_{i j}$;

$r_{i} \quad$ The probability of returning the product before customer use when it is sold in an internet-based sales channel $(i=1,2, \ldots, m, r p)$;

rrc The probability of returning the product after customer use;

rrp The rate of converting returned products to repaired ones;

$\pi_{R} \quad$ Retailer's profit function;

$\pi_{R}(i) \quad$ Retailer's profit gained from product $i$;

$\pi_{i} \quad$ Profit of manufacturer $i$ function $(i=1,2, \ldots, m, r p)$;

$\pi_{(i(I))} \quad$ Profit of manufacturer resulting from internet-based purchase;

$\pi_{(i(W))} \quad$ Profit of manufacturer $i$ resulting from retailers' channel;

$X_{i} \quad$ A binary variable (if manufacturer $i$ has an internet-based sales channel, it is 1 and is 0 otherwise) $(i=1,2, \ldots, m, r p)$.

\section{Problem formulation}

The model includes a single-period inventory and a pricing model in a closed-loop supply chain with $m$ manufacturers and a repair center, as shown in Figure 1. Each manufacturer and repair center can provide their products through a common retailer while they may have their own internet-based sales channel.

The problem model is a multi-objective maximization problem aimed at optimizing the profit gained by retailers, manufacturers, and repair centers considering three strategies:

1. Decentralized supply chain considering Nash game structure;

2. Decentralized supply chain considering Stackelberg structure in which manufacturers and repair centers are leaders;

3. Decentralized supply chain considering Stackelberg structure in which a retailer is leader.

In the proposed model, the demand is defined as a function of price and service level of products in a retailer's channel. Demand of product $i$ in an internetbased channel is defined as in Eq. (1):

$$
\begin{aligned}
d_{i d}= & a_{i d}-b_{i d} P_{i d}+\sum_{\substack{j=1 \\
, j=r p}}^{m}\left(\theta_{i j r} P_{j r}-\gamma_{i j} \nu_{j}\right) \\
& +\sum_{\substack{j=1 \\
j=r p, j \neq i}}^{m} \theta_{i j d} P_{j d}
\end{aligned}
$$

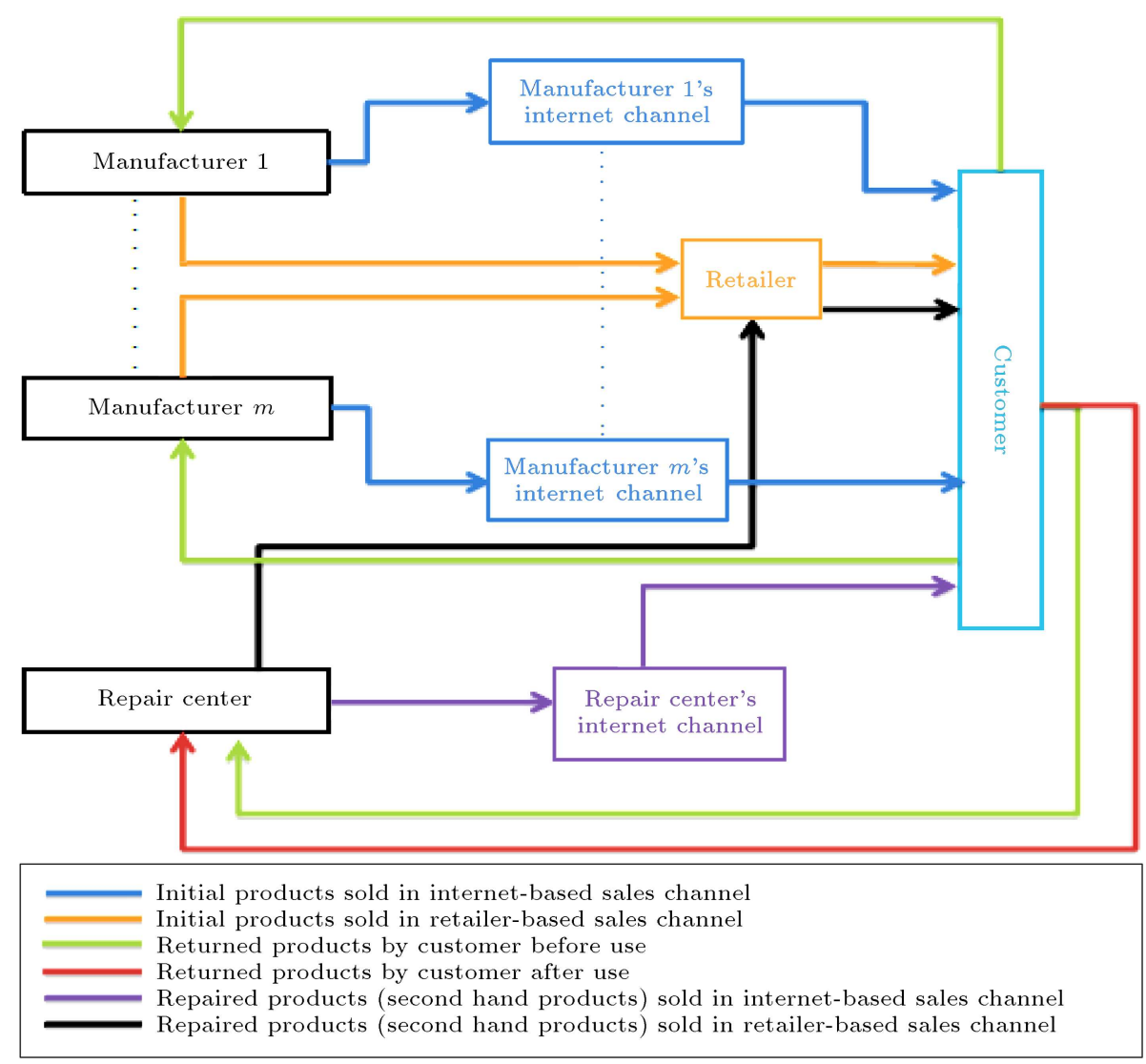

Figure 1. The structure of the supply chain under study. 
where the first term denotes potential demand of product $i$ in an internet-based channel. The second term represents how product price affects its demand in an internet-based channel. The third term shows the effect of price and service level of products offered in a retailer channel. Finally, the fourth term demonstrates how price of other products in an internet-based channel impacts the demand of product $i$ in this channel.

Similarly, demand for the $i$ th product in a retailer's channel is defined according to Eq. (2).

$$
\begin{aligned}
d_{i r}= & a_{i r}-b_{i r} P_{i r}+\gamma_{i i} \nu_{i} \\
& +\sum_{\substack{j=1 \\
j=r p, i \neq j}}^{m}\left(\beta_{i j r} P_{j r}-\gamma_{i j} \nu_{j}\right) \\
& +\sum_{\substack{j=1 \\
j=r p}}^{m} \beta_{i j d} P_{j d} .
\end{aligned}
$$

The terms utilized in Eq. (2) are the same as those in Eq. (1).

A number of sold products are returned to repair centers after being used by customers. The demand for return $(d r c)$ is defined as a percentage of total sold products (rcc) according to Eq. (3):

$$
\begin{aligned}
d r c= & \left(\sum_{i=1}^{m} \min \left(D_{i d}, Y_{i d}\right)\right. \\
& \left.+\sum_{i=1}^{m} \min \left(D_{i r}, Y_{i r}\right)\right) \times r r c
\end{aligned}
$$

where the terms in parentheses show the total sold products in an internet-based channel (the first term) and a retailer's channel (the second term). It must be noted that the amount of sold products in a channel equals the minimum level demand and its corresponding amount of delivered product in the channel. The percentage of sold products returned after use is represented by rrc.

To make the demand for a stochastic value, $\varepsilon r c$, a continuous random variable is used as shown in Eq. (4) [11].

$$
D r c=d r c \times \varepsilon r c .
$$

Second-hand products are purchased from customers at Prc. In our model, Prc is defined as a percentage (rprc\%) of average sold products according to Eq. (5):

$$
\operatorname{prc}=\operatorname{rprc}\left(\frac{1}{2 m} \sum_{j=r, d} \sum_{i=1}^{m} P_{i j}\right) .
$$

Demand for second-hand repaired products is linearly proportional to price and service levels of products. Eqs. (6) and (7) represent the demand formulation for internet-based and retailer's channels, respectively:

$$
\begin{aligned}
d_{r p d}= & a_{r p d}-b_{r p d} P_{r p d} \\
& +\sum_{\substack{j=1 \\
, j=r p}}^{m}\left(\theta_{r p j r} P_{j r}-\gamma_{r p j} \nu_{j}\right) \\
& +\sum_{j=1}^{m} \theta_{r p j d} P_{j d}, \\
d_{r p r}= & a_{r p r}-b_{r p r} P_{r p r}+\gamma_{r p r p} \nu_{r p} \\
& +\sum_{j=1}^{m}\left(\beta_{r p j r} P_{j r}-\gamma_{r p j} \nu_{j}\right) \\
& +\sum_{\substack{j=1 \\
j=r p}}^{m} \beta_{r p j d} P_{j d} .
\end{aligned}
$$

Details of Eqs. (6) and (7) are the same as those of Eq. (1).

The total sold second-hand products should be less than the number of returned products according to Eq. (8):

$$
Y_{r p d}+Y_{r p d}<D_{r c}
$$

Obviously, the price of second-hand products must be less than that of the initial products; thus, the following constraint (Eq. (9)) must be satisfied:

$$
P_{r p r}, P_{r p d} \leq P_{i r}, P_{i d}(i=1,2, \ldots, m) .
$$

As seen in equations describing demand (Eqs. (1), (2), $(3),(6),(7))$, the demand of product $i$ in channel $j$ $\left(d_{i j}\right)$ is a function of undergoing items:

1. Market potential for product $i$ in the corresponding channel $j\left(a_{i j}\right)$ (which is a portion of total market potential (a) according to Eq. (10)):

$$
a_{i j}=\alpha_{i j} . a .
$$

Eq. (9) is valid as far as Eq. (11) is met:

$$
\sum_{i=1}^{m} \sum_{j=r, d} \alpha_{i j}=1 \text {. }
$$

2. The price of product which is considered with an impact factor equal to self-sensitivity parameter of product $i$ in channel $j\left(b_{i j}\right)$.

3. The price of rival products as well as that of the same product in rival channels. It is included via impact factors modelled by inter-brand and interbrand-inter-channel sensitivities $(\beta, \theta)$.

4. The service level offered for product $i$. Its influence is determined by sensitivity to the service level offered for product $i$ in a retailer's channel $\left(\gamma_{i i}, \gamma_{i}\right)$.

5. The service level offered for rival products in a retailer's channel $\left(v_{j}\right)$. It affects the price through defined sensitivity parameter between a retailer's service level for product $j$ and demand for product $i$ in a retailer's and internet-based channels $\left(\gamma_{i j}\right)$. 
The demand derived for product $i$ in channel $j\left(d_{i j}\right)$ is definite; however, in real world, there is nothing definite. As a result, demand is transformed to a stochastic value using $\varepsilon_{i j}$ random variable. The probabilistic demand is obtained from Eq. (12) [11].

$$
D_{i j}=d_{i j} \times \varepsilon_{i j} \quad(i=1,2, \ldots, m, r p, \quad j=r, d),
$$

where $m$ denotes the number of substitutable products, and $r p$ represents repaired (second-hand) products.

The amount of orders for $d_{i j}$, i.e., $q_{i j}$, is determined using Eq. (13) based on customer demand for product $i$ in channel $j\left(d_{i j}\right)$ and risk factor $Z_{i j}$ (for product $i$ in channel $j$ ). Risk factor equals 1 if there is no risk. Higher risk factors demonstrate higher risktaking potential of people who order, whereas the lower values illustrate lower risk-taking potential.

$$
q_{i j}=z_{i j} \times D_{i j} \quad(i=1,2, \ldots, m, r p, \quad j=r, d) .
$$

The proposed model is able to generate optimal order values for known values of risk factor.

It is clear that a manufacturer's production may not completely match order as demand is a stochastic variable. Hence, the deliverable amount of $q_{i j}$ is converted into a stochastic variable using $y_{i j}$ continuous random variable, which is denoted by $Y_{i j}$ and is defined according to Eq. (14).

$$
Y_{i j}=q_{i j} \times y_{i j} \quad(i=1,2, \ldots, m, r p, \quad j=r, d) .
$$

Furthermore, it is assumed that a portion of products $\left(R_{i}\right)$ sold in the internet-based sales channel is returned by the customer before use. It is transformed to a stochastic value $\left(r_{i}\right)$ using $\varepsilon_{i}$ as shown by Eq. (15):

$$
r_{i}=R_{i} \cdot \varepsilon_{i} \quad(i=1,2, \ldots, m, r p)
$$

A customer does not pay while a manufacturer bears the cost of the return of these products $\left(c r_{i}\right)$. Therefore, considering returned products, a manufacturer gains profit through selling $1-r_{i}$ percent of sold products. A manufacturer should cover three types of expenses associated with each product $i$ : the cost of production of each unit $\left(c p_{i}\right)$, the cost of distribution across an internet-based channel $\left(c d d_{i}\right)$, and cost of distribution over retailers' channel $\left(c d r_{i}\right)$. As the model is a single-period one, at the end of period, unsold products in the internet-based channel will be considered as surplus. The manufacturer has to sell the surplus at a lower price $\left(s_{i j}\right)$ during period price $\left(P_{i j}\right)$. On the other hand, the number of products provided by the manufacturer might be more than that of ordered products as a consequence of its stochastic nature. In such a circumstance, surplus of product $i$ in channel $j$ would be offered at a lower price $\left(m_{i j}\right)$ during period price $\left(P_{i j}\right)$. In contrast, since demand, order and deliverable rates are stochastic, the demand for product $i$ in channel $j$ might be more than the number of products. In such a condition, $t_{i j}$ must be paid for each unit of shortage in the products. Manufacturer $i$ offers retailers his products at a wholesale price $\left(W_{i}\right)$. In this study, it is assumed that $W_{i}$ value is determined based on long-term contracts made between a retailer and a manufacturer; thus, it is assumed to be constant, as Kurata et al. (2007) [5] made the same assumption.

Based on the aforementioned information, the total profit function of a manufacturer could be shown in the form of Eq. (16):

$$
\pi_{i}=X_{i} \pi_{i(I)}+\pi_{i(w)},
$$

where $\pi_{i(i)}$ is the profit obtained from internet-based sales channels, and $\pi_{i(W)}$ is the profit obtained from the retailer's channels of the $i$ th manufacturer.

$\pi_{i(I)}$ is defined by Eq. (17):

$$
\begin{aligned}
\pi_{i(I)}= & E\left(\left(P_{i d}\left(\min \left[D_{i d}, \min \left\{q_{i d}, Y_{i d}\right\}\right] \times\left(1-r_{i}\right)\right)\right.\right. \\
& -c d d_{i} \min \left[D_{i d}, \min \left\{q_{i d}, Y_{i d}\right\}\right]-c p_{i} Y_{i d} \\
& -c r_{i} \min \left[D_{i d}, \min \left\{q_{i d}, Y_{i d}\right\}\right] \times r_{i} \\
& +m_{i d} \max \left\{Y_{i d}-q_{i d}, 0\right\} \\
& +s_{i d} \max \left[\min \left\{q_{i d}, Y_{i d}\right\}\right. \\
& \left.+\min \left\{D_{i d}, \min \left\{q_{i d}, Y_{i d}\right\}\right\} \times r_{i}-D_{i d}, 0\right] \\
& -t_{i d} \max \left[D_{i d}-\min \left\{q_{i d}, Y_{i d}\right\}\right. \\
& \left.-\min \left\{D_{i d}, \min \left\{q_{i d}, Y_{i d}\right\} \times r_{i}, 0\right]\right)
\end{aligned}
$$

where $\left(\min \left[D_{i d}, \min \left\{q_{i d}, Y_{i d}\right\}\right] \times\left(1-r_{i}\right)\right)$ is the actual value of product $i$ sales in the internetbased channel when returned products are subtracted from the total value. As a result, $P_{i d}\left(\min \left[D_{i d}, \min \left\{q_{i d}, Y_{i d}\right\}\right] \times\left(1-r_{i}\right)\right)$ is the income of sales, while $c d d_{i} \min \left[D_{i d}, \min \left\{q_{i d}, Y_{i d}\right\}\right]$ is the cost of distributing the product sold in an internet-based channel. The production cost is defined by $c p_{i} Y_{i d}$. Since $r_{i} \%$ of sold product $i$ in an internet-based channel is returned, $c r_{i} \min \left[D_{i d}, \min \left\{q_{i d}, Y_{i d}\right\}\right] \times r_{i}$ is the cost of product return. The profit obtained through selling those products, which are not allocated till the end of period is denoted by $m_{i d} \max \left\{Y_{i d}-q_{i d}, 0\right\}$. The profit made through selling surplus unsold products at the end of period is represented by $s_{i d} \max \left[\min \left\{q_{i d}, Y_{i d}\right\}+\right.$ $\left.\min \left\{D_{i d}, \min \left\{q_{i d}, Y_{i d}\right\}\right\} \times r_{i}-D_{i d}, 0\right]$. Finally, the shortage cost which includes lost sales is obtained by $t_{i d} \max \left[D_{i d}-\min \left\{q_{i d}, Y_{i d}\right\}-\min \left\{D_{i d}, \min \left\{q_{i d}, Y_{i d}\right\} \times\right.\right.$ $\left.r_{i}, 0\right]$.

Eq. (18) formulates the manufacturer's profit obtained from selling product $i$ to retailers (wholesale 
profit):

$$
\begin{aligned}
\pi_{i(w)}= & E\left[\left(w_{i}-c d r_{i}\right)\right) \min \left\{q_{i r}, Y_{i r}\right\}-c p_{i} Y_{i r} \\
& \left.+m_{i r} \max \left\{Y_{i r}-q_{i r}, 0\right\}\right] .
\end{aligned}
$$

In Eq. (18), $\left.\left(w_{i}-c d r_{i}\right)\right) \min \left\{q_{i r}, Y_{i r}\right\}-c p_{i} Y_{i r}$ is retailers' sales profit, and $m_{i r} \max \left\{Y_{i r}-q_{i r}, 0\right\}$ is the profit gained via selling unallocated inventory.

Profit function of a retailer is defined by Eq. (19):

$$
\begin{aligned}
\pi_{R} & =\sum_{i=1, r p}^{i=m} \pi_{R(i)} \\
& =\sum_{\substack{i=1, i=r p}}^{m} E\left(P_{i r} \min \left\{D_{i r}, \min \left\{q_{i r}, Y_{i r}\right\}\right\}\right. \\
& -\left[W_{i}+C\left(v_{i}\right)\right] \min \left\{q_{i r}, Y_{i r}\right\} \\
& +s_{i r} \max \left\{\min \left\{q_{i r}, Y_{i r}\right\}-D_{i r}, 0\right\} \\
& \left.-t_{i r} \max \left\{D_{i r}-\min \left\{q_{i r}, Y_{i r}\right\}, 0\right\}\right],
\end{aligned}
$$

where $P_{i r} \min \left\{D_{i r}, \min \left\{q_{i r}, Y_{i r}\right\}\right\}$ is the income of product sales, and $\left[W_{i}+C\left(v_{i}\right)\right] \min \left\{q_{i r}, Y_{i r}\right\}$ is the total payment including cost of purchasing products at a wholesale price and the cost of services provided for customers. Moreover, $s_{i r} \max \left\{\min \left\{q_{i r}, Y_{i r}\right\}-D_{i r}, 0\right\}$ denotes the profit gained from surplus product sales, while $t_{i r} \max \left\{D_{i r}-\min \left\{q_{i r}, Y_{i r}\right\}, 0\right\}$ is the cost of shortage in a retailer's channel.

Profit function for a repair center is represented by Eq. (20):

$$
\begin{aligned}
\pi_{r p}= & X_{r p} \pi_{r p(I)}+\pi_{r p(W)}-c c \times D r c \\
& -(P r c+c r r c) D r c,
\end{aligned}
$$

where $\pi_{r p(W)}$ is the profit of selling second-hand products to a retailer's channel, and $\pi_{r p(I)}$ denotes the profit gained through selling second-hand products in an internet-based sales channel (if there is an internetbased sales channel, i.e., $X_{r p}=1$ ). Besides, $c c \times D r c$ is the cost imposed by the classification of second-hand products, while $(\operatorname{Prc}+\mathrm{crrc}) \operatorname{Drc}$ is the cost of returning and purchasing second-hand products. $\pi_{r p(W)}$ and $\pi_{r p(I)}$ are defined as in Eqs. (21) and (22), respectively:

$$
\begin{aligned}
& \pi_{r p(w)}= E\left[\left(w_{r p}-c d r_{r p}\right) \min \left\{q_{r p r}, Y_{r p r}\right\}\right. \\
&\left.+m_{r p r} \max \left\{Y_{r p r}-q_{r p r}, 0\right\}-c r p Y_{r p r}\right],( \\
& \pi_{r p(I)}=E\left(\left(P _ { r p d } \left(\min \left\{D_{r p d}, \min \left\{q_{r p d}, Y_{r p d}\right\}\right\}\right.\right.\right. \\
&\left.\times\left(1-r_{r p}\right)\right)-c d d_{r p} \min \left\{D_{r p d}, \min \left\{q_{r p d}, Y_{r p d}\right\}\right\} \\
&-c r p \min Y_{r p d}-c r r p \min \left\{D_{r p d},\right.
\end{aligned}
$$

$$
\begin{aligned}
& \left.\min \left\{q_{r p d}, Y_{r p d}\right\}\right\} \times r_{r p} \\
& +m_{r p d} \max \left\{Y_{r p d}-q_{r p d}, 0\right\} \\
& +s_{r p d} \max \left\{\min \left\{q_{r p d}, Y_{r p d}\right\}\right. \\
& +\min \left\{D_{r p d}, \min \left\{q_{r p d}, Y_{r p d}\right\}\right\} \times r_{r p} \\
& \left.-D_{r p d}, 0\right\}-t_{r p d} \max \left\{D_{r p d}-\min \left\{q_{r p d}, Y_{r p d}\right\}\right. \\
& \left.\left.-\min \left\{D_{r p d}, \min \left\{q_{r p d}, Y_{r p d}, 0\right\}\right\} \times r_{r p}, 0\right\}\right) .
\end{aligned}
$$

In Eqs. (21) and (22), definitions of the terms are the same as those in Eqs. (19) and (17).

Prior to solving the model based on various strategies, some assumptions must be mentioned.

- Assumption 1: Assumption 1 is stated based on Eqs. (23) and (24).

$$
\begin{aligned}
& b_{i d}> \sum_{j=1, r p}^{m} \theta_{i j r}+\sum_{\substack{j=1, r p \\
i \neq j}}^{m} \theta_{i j d} \\
&(i=1,2, \ldots, m, r p), \\
& b_{i r}>\sum_{\substack{j=1 \\
j=r p, i \neq j}}^{m} \beta_{i j r}+\sum_{\substack{j=1 \\
j=r p}}^{m} \beta_{i j d} \\
&(i=1,2, \ldots, m, r p) .
\end{aligned}
$$

It is emphasized that the influence of product price in a specific channel $\left(P_{i j}\right)$ on its demand $\left(D_{i j}\right)$ is more important than the total influence made by the price of other products and product itself in the rival channel on the demand of product $i$ in channel $j$.

- Assumption 2: Assumption 2 is based on Eq. (25):

$$
\pi_{r p}, \pi_{R}, \pi_{i}(i=1,2, \ldots, m)>0 .
$$

Assumption 2 guarantees continuous cooperation of supply chain members.

To solve the problem, three different strategies are considered, all of which are based on the decentralized supply chain.

\section{Decentralized supply chain}

\subsection{Nash game structure}

In Nash game, all players have the same power. Their decisions are made such that their profit is maximized simultaneously. Therefore, the goal is to maximize objective functions (Eq. (26)) simultaneously:

$$
\begin{aligned}
& \max \pi_{R} \\
& \max \pi_{i}(i=1,2, \ldots, m) \\
& \max \pi_{r p} .
\end{aligned}
$$

While Constraints (27)-(43) are considered: 


$$
\begin{aligned}
d_{i d}= & a_{i d}-b_{i d} P_{i d}+\sum_{\substack{j=1 \\
j=r p}}^{m}\left(\theta_{i j r} P_{j r}-\gamma_{i j} \nu_{j}\right) \\
& +\sum_{\substack{j=1 \\
j=r p, j \neq i}}^{m} \theta_{i j d} P_{j d}, \\
d_{i r}= & a_{i r}-b_{i r} P_{i r}+\gamma_{i i} \nu_{i} \\
& +\sum_{j=1}^{m} \underset{j=r p, i \neq j}{m}\left(\beta_{i j r} P_{j r}-\gamma_{i j} \nu_{j}\right) \\
& +\sum_{\substack{j=1 \\
j=r p}}^{m} \beta_{i j d} P_{j d}, \\
d r c= & \left(\sum_{i=1}^{m} \min \left(D_{i d}, Y_{i d}\right)\right. \\
& \left.+\sum_{i=1}^{m} \min \left(D_{i r}, Y_{i r}\right)\right) \times r r c,
\end{aligned}
$$

$D r c=d r c \times \varepsilon r c$,

$$
\operatorname{prc}=\operatorname{rprc}\left(\frac{1}{2 m} \sum_{j=r, d} \sum_{i=1}^{m} P_{i j}\right),
$$

$$
d_{r p d}=a_{r p d}-b_{r p d} P_{r p d}
$$

$$
\begin{aligned}
& +\sum_{\substack{j=1 \\
j=r p}}^{m}\left(\theta_{r p j r} P_{j r}-\gamma_{r p j} \nu_{j}\right) \\
& +\sum_{j=1}^{m} \theta_{r p j d} P_{j d}
\end{aligned}
$$

$$
d_{r p r}=a_{r p r}-b_{r p r} P_{r p r}+\gamma_{r p r p} \nu_{r p}
$$

$$
\begin{aligned}
& +\sum_{j=1}^{m}\left(\beta_{r p j r} P_{j r}-\gamma_{r p j} \nu_{j}\right) \\
& +\sum_{\substack{j=1 \\
j=r p}}^{m} \beta_{r p j d} P_{j d},
\end{aligned}
$$

$a_{i j}=\alpha_{i j} \cdot a$,

$\sum_{i=1}^{m} \sum_{j=r, d} \alpha_{i j}=1$

$D_{i j}=d_{i j} \times \varepsilon_{i j} \quad i=1,2, \ldots, m, r p, \quad j=r, d$,

$q_{i j}=z_{i j} \times D_{i j} \quad i=1,2, \ldots, m, r p, \quad j=r, d$,

$Y_{i j}=q_{i j} \times y_{i j} \quad i=1,2, \ldots, m, r p, \quad j=r, d$,

$Y_{r p d}+Y_{r p d}<D_{r c}$

$P_{r p r}, P_{r p d} \leq P_{i r}, P_{i d} \quad(i=1,2, \ldots, m)$,

$r_{i}=R_{i} \cdot \varepsilon_{i}$

$\pi_{r p}, \pi_{R}, \pi_{i}(i=1,2, \ldots, m)>0$,

$P_{i j}, q_{i j} \geq 0$.
The outcome of the game is not clear when an equilibrium solution does not exist, whereas if there is an equilibrium solution, a decision-maker is able to find the optimal solution. Cachon and Netessine (2004) [29] proposed a useful method for investigating the existence and uniqueness of equilibrium solution. Topkis (1979 and 1998) [22,23] and Milgrom and Roberts (1990) [24] utilized the following constraints to examine the existence and uniqueness of the equilibrium solution. In the following, the constraints associated with the existence and uniqueness of Nash equilibrium solution are presented; subsequently, the problem is solved in the Nash structure.

Definition 1 [16]: A twice continuously differentiable payoff function is super modular if and only if $\partial^{2} \pi_{i} / \partial x_{i} \partial x_{j} \geq 0$ for all $x$ and $i \neq j$. If players' profit function is super modular, the game is called a super modular game.

Lemma 1 [16]: If a game is super modular, there is at least one Nash equilibrium solution.

Lemma 2 [16]: If an equilibrium solution exists and $\left|\partial^{2} \pi_{k} / \partial x_{k} \partial x_{k}\right|>\sum_{i=1, i \neq k}^{n}\left|\partial^{2} \pi_{k} / \partial x_{k} \partial x_{j}\right|$ is satisfied, this point is unique.

Theorem 1: $\pi_{r p}, \pi_{R}, \pi_{i}(i=1,2, \ldots, m)$ are super modular in $P_{i j}(i=1,2, \ldots, m ; j=r, d)$.

The proposed model is super modular because $\partial^{2} \pi_{i} / \partial x_{i} \partial x_{j} \geq 0\left(x_{i}, x_{j}=P_{i j}, q_{i j} i=1,2,3, \ldots, m, r p\right.$, $j=r, d)$,

Theorem 2: If criteria as Eqs. (44) and (45) are satisfied, the problem has a unique solution:

$$
\begin{gathered}
\left|\partial^{2} \pi_{R} / \partial P_{i r} \partial P_{i r}\right|>\sum_{j=r, d} \sum_{\substack{k=1, k \neq i \\
k=r p}}^{m}\left|\partial^{2} \pi_{R} / \partial P_{i r} \partial P_{k j}\right| \\
(i=1,2, \ldots, m, r p), \\
\left|\partial^{2} \pi_{i} / \partial P_{i d} \partial P_{i d}\right|>\sum_{j=r, d} \sum_{\substack{k=1, k \neq i \\
k=r p}}^{m}\left|\partial^{2} \pi_{i} / \partial P_{i d} \partial P_{k j}\right| \\
(i=1,2, \ldots, m, r p) .
\end{gathered}
$$

In order to solve the model in the Nash structure, it is only required to solve a multi-objective problem shown in Eq. (46) considering the constraints imposed by Eqs. (27)-(43):

$\max \pi_{R}$

$\max \pi_{i}(i=1,2, \ldots, m)$ 


$$
\max \pi_{r p}
$$

A variety of methods has been proposed to solve such problems, including metaheuristic methods. However, considering Theorem 2 as a default fact, the best and simplest method for deriving definite optimal values for decision variables is using Kuhn-Tucker method [25]. Additionally, a Kuhn-Tucker method avoids the local optimum that might be provided by metaheuristic methods.

\subsection{Stackelberg game}

Contrary to Nash game, in Stackelberg game, players have different powers. In this paper, first off, a scenario is considered in which manufacturers and repair centers are leaders, while retailers are followers. Afterwards, the second scenario is investigated in which a retailer is the leader and two other players are followers.

In the following, the constraints associated with the existence and uniqueness of Stackelberg game solutions are presented.

Theorem 3: $\quad \pi_{R}$ is concave with respect to $P_{i r}$ if the following condition (Eq. (47)) holds [5]:

$$
\begin{gathered}
M_{j r} z_{j r}\left(-b_{j r}+2 \sum_{\substack{j=1 \\
, j=r p, j \neq i}}^{m} \beta_{j i r}\right)<0 \\
j=1,2, \ldots, m, r p
\end{gathered}
$$

where $M_{i j}=E\left(\varepsilon_{i j} \min \left(1, z_{i j} \min \left(1, y_{i j}\right)\right)\right)$.

Theorem 4. $\pi_{i}$ is concave with respect to $P_{i d}$ according to Eq. (48) [5]:

$$
-2 b_{i d} M_{i d}\left(1-r_{i}\right)<0, \quad i=1,2, \ldots, m, r p .
$$

Theorem 5. In the Stackelberg game, the equilibrium solution is unique if the following conditions (Eq. (49) and (50)) hold [16]:

$$
\begin{aligned}
& \left|\sum_{j=r, d}^{n} \sum_{\substack{i=1 \\
, i=r p, i \neq j}}^{m} M_{i j} z_{i j}\left(-2 b_{i j}+\beta_{j i r}\right)\right| \\
& \quad<\left|M_{k r} z_{k r}\left(-b_{k r}+2 \sum_{\substack{j=1 \\
, j=r p, j \neq i}}^{m} \beta_{k i r}\right)\right| \\
& \quad k=1,2, \ldots m, r p \\
& \left|-2 b_{i d} M_{i d}\left(1-r_{i}\right)\right|>0, \quad i=1,2, \ldots, m, r p .
\end{aligned}
$$

4.2.1. Stackelberg game with manufacturers and repair center as leaders (first scenario):

In the first scenario, manufacturers and repair centers are more powerful in the market. That is to say, they decide on price; then, a retailer makes a decision according to the leaders' preferences. Therefore, in the first step, a problem with objectives shown in Eq. (51) and considering constraints represented by Eqs. (27)-(43) is solved. For this purpose, Kuhn-Tucker conditions are utilized to obtain the optimal values for decision variations $P_{i d}, q_{i d}(i=1,2, \ldots, m, r p)$ in terms of $P_{i r}, q_{i r}(i=1,2, \ldots, m, r p)[25]$.

$$
\begin{aligned}
& \max \pi_{i}(i=1,2, \ldots, m) \\
& \max \pi_{r p} .
\end{aligned}
$$

By substituting $P_{i d}, q_{i d}(i=1,2, \ldots, m, r p)$ derived from solving Eq. (51) in Eq. (19) and solving a problem whose objective function is Eq. (52) using the KuhnTucker method, the optimal decision values $P_{i r}, q_{i r}$ $(i=1,2, \ldots, m, r p)$ are obtained. Constraint equations (Eqs. (27)-(43)) must be noticed.

$$
\max \pi_{R} \text {. }
$$

The optimal values calculated through solving problem equation (Eq. $(52)),\left(P_{i r}, q_{i r}(i=1,2, \ldots, m, r p)\right.$, are substituted into equations regarding $P_{i d}, q_{i d}(i=$ $1,2, \ldots, m, r p)$ which are obtained from Eq. (51). As a result, optimal values of $P_{i d}, q_{i d}(i=1,2, \ldots, m, r p)$ are calculated [26,27]. A closed-form expression for the optimal retail prices is not reported here because of its complexity.

\subsubsection{Stackelberg game with a retailer as a leader (second scenario)}

In the second scenario, retailers are dominant in the market. Pricing decisions are made by retailers prior to other players. Following a retailer's decision, manufacturers and repair centers may decide on price. Therefore, a problem with objectives shown in Eq. (53) and considering constraints represented by Eqs. (27)-(43) is solved. For this purpose, Kuhn-Tucker conditions are utilized to obtain the optimal values for variations in $P_{i r}, q_{i r}(i=1,2, \ldots, m, r p)$ decisions in terms of $P_{i d}$, $q_{i d}(i=1,2, \ldots, m, r p)$ :

$\max \pi_{R}$

By substituting $P_{i r}, q_{i r}(i=1,2, \ldots, m, r p)$ derived from solving Eq. (53) into equations related to $\pi_{i}$ (Eqs. (16) and (20)) and solving a problem whose objective function is Eq. (54) using Kuhn-Tucker method, the optimal decision values are obtained. It must be noted that the constraints represented by Eqs. (27)(43) must be noticed.

$$
\begin{aligned}
& \max \pi_{i}(i=1,2, \ldots, m) \\
& \max \pi_{r p} .
\end{aligned}
$$

The optimal values of $P_{i d}, q_{i d}(i=1,2, \ldots, m, r p)$ 
calculated via solving problem equation (Eq. (54)) are substituted into equations regarding $P_{i r}, q_{i r}(i=$ $1,2, \ldots, m, r p)$. As a result, the optimal values of $P_{i r}$, $q_{\text {ir }}(i=1,2, \ldots, m, r p)$ are calculated [26,27]. For the sake of simplicity, the detailed equations are avoided here.

\section{Numerical example}

In this section, a numerical example is developed to demonstrate a managerial perspective which results from the proposed model. To avoid unfavorable complexity and facilitate required comparisons, the numerical example is considered for a case in which there are identical substitutable products from two manufacturers. It is also assumed that two manufacturers have internet-based and retailer's sales channels. The base information is adopted from [28,5]. The following values are assigned to the model parameters:

$$
\begin{aligned}
& m=2, \quad X_{1}, X_{2}=1, \quad s_{i r}, s_{i d}=0.5, \quad t_{i r}, t_{i d}=0.5, \\
& m_{i d}, m_{i r}=0.5 \quad(i=1,2), \\
& \theta_{i j r}, \theta_{i j d}, \beta_{i j r}, \beta_{i j d}, \beta_{r p d}=1, \\
& \gamma_{i j}=0.3, \quad \gamma_{i j}=0.7, \\
& R_{i}=0.1, \quad c_{d d i}=2, \quad c_{p i}=2, \quad c_{r i}=2, \\
& b_{i d}=b_{i r}=10, \quad z_{i j}=1, \quad v_{i}=3, \quad \eta_{i j}=0.5 \\
& (i=1,2, r p j=r, d) \\
& c_{c}=1, \quad c_{r r c}=2, \quad c_{r p}=3, \quad a=400, \quad \alpha_{i j}=0.25, \\
& a_{r p}=100, \quad \alpha_{r p j}=0.5, \quad r_{r c}=0.01, \quad W_{1}=W_{2}=15, \\
& W_{r p}=10, \quad r p r c=0.4, \\
& r r c=0.0 .01, \quad \operatorname{rrp}=0.6, \quad S_{r p r}=S_{r p d}=0.4, \\
& t_{r p r}=t_{r p d}=0.4, \quad m_{r p d}=m_{r p r}=0.4 .
\end{aligned}
$$

By substituting numerical values in Eqs. (16)-(22), we simplify expressions and transform them to calculable expressions.

Eq. (55) represents a retailer's profit. To calculate min terms in the equation, it is separated into different intervals and is transformed into an integral.

$$
\begin{aligned}
\pi_{R}= & \int_{1-\tilde{\varepsilon}}^{1+\tilde{\varepsilon}} \int_{1-\tilde{y}}^{1} d_{1 r} \varepsilon_{1 r}\left(P_{1 r} y_{1 r}-17.25 y_{1 r}-0.5\right) \\
& f\left(y_{1 r}\right) f\left(\varepsilon_{1 r}\right) d y_{1 r} d \varepsilon_{1 r}+\int_{1-\tilde{\varepsilon}}^{1+\tilde{\varepsilon}} \int_{1-\tilde{y}}^{1} \\
& d_{2 r} \varepsilon_{2 r}\left(P_{2 r} y_{2 r}-17.25 y_{2 r}-0.5\right) f\left(y_{2 r}\right) f\left(\varepsilon_{2 r}\right)
\end{aligned}
$$

$$
\begin{aligned}
& d y_{2 r} d \varepsilon_{2 r}+\int_{1-\tilde{\varepsilon}}^{1+\tilde{\varepsilon}} \int_{1-\tilde{y}}^{1} d_{r p r} \varepsilon_{r p r}\left(P_{r p r} y_{r p r}\right. \\
& \left.-17.25 y_{r p r}-0.5\right) f\left(y_{r p r}\right) f\left(\varepsilon_{r p r}\right) d y_{r p r} d \varepsilon_{r p r} \\
& +\int_{1-\tilde{\varepsilon}}^{1+\tilde{\varepsilon}} d_{1 r} \varepsilon_{1 r}\left(P_{1 r}-17.75\right) f\left(\varepsilon_{1 r}\right) d \varepsilon_{1 r} \\
& +\int_{1-\tilde{\varepsilon}}^{1+\tilde{\varepsilon}} d_{2 r} \varepsilon_{2 r}\left(P_{2 r}-17.75\right) f\left(\varepsilon_{2 r}\right) d \varepsilon_{2 r} \\
& +\int_{1-\tilde{\varepsilon}}^{1+\tilde{\varepsilon}} d_{r p r} \varepsilon_{r p r}\left(P_{r p r}-17.75\right) f\left(\varepsilon_{r p r}\right) d \varepsilon_{r p r} .
\end{aligned}
$$

The wholesale profit of manufacturer 1 is shown by Eq. (56):

$$
\begin{aligned}
\pi_{1(w)}= & \int_{1-\tilde{\varepsilon}}^{1+\tilde{\varepsilon}} \int_{1-\tilde{y}}^{1} 7 d_{1 r} \varepsilon_{1 r} y_{1 r} f\left(y_{1 r}\right) f\left(\varepsilon_{1 r}\right) d y_{1 r} d \varepsilon_{1 r} \\
& +\int_{1-\tilde{\varepsilon}}^{1+\tilde{\varepsilon}} \int_{1}^{1+\tilde{y}} d_{1 r} \varepsilon_{1 r}\left(47.5+2 y_{1 r}\right) \\
& f\left(y_{1 r}\right) f\left(\varepsilon_{1 r}\right) d y_{1 r} d \varepsilon_{1 r}
\end{aligned}
$$

Eq. (57) denotes the first manufacturer's profit obtained from internet-based sales channels.

$$
\begin{aligned}
\pi_{1(I)}= & \int_{1-\tilde{\varepsilon}}^{1+\tilde{\varepsilon}} \int_{1-\tilde{y}}^{1} d_{1 d} \varepsilon_{1 d}\left(0.9 P_{1 d} y_{1 d}-7.65 y_{1 d}\right. \\
& -0.5) f\left(y_{1 d}\right) f\left(\varepsilon_{1 d}\right) d y_{1 d} d \varepsilon_{1 d} \\
& +\int_{1-\tilde{\varepsilon}}^{1+\tilde{\varepsilon}} \int_{1}^{1+\tilde{y}} d_{1 d} \varepsilon_{1 d}\left(0.9 P_{1 d}-6.65\right. \\
& \left.-1.5 y_{1 d}\right) f\left(y_{1 d}\right) f\left(\varepsilon_{1 d}\right) d y_{1 d} d \varepsilon_{1 d} .
\end{aligned}
$$

Thus, the total profit of manufacturer 1 is calculated as in Eq. (58):

$$
\begin{aligned}
\pi_{1}= & \pi_{1(w)}+\pi_{1(I)}=\int_{1-\tilde{\varepsilon}}^{1+\tilde{\varepsilon}} \int_{1-\tilde{y}}^{1} 7 d_{1 r} \varepsilon_{1 r} y_{1 r} f\left(y_{1 r}\right) \\
& f\left(\varepsilon_{1 r}\right) d y_{1 r} d \varepsilon_{1 r}+\int_{1-\tilde{\varepsilon}}^{1+\tilde{\varepsilon}} \int_{1}^{1+\tilde{y}} d_{1 r} \varepsilon_{1 r}\left(47.5+2 y_{1 r}\right) \\
& f\left(y_{1 r}\right) f\left(\varepsilon_{1 r}\right) d y_{1 r} d \varepsilon_{1 r}+\int_{1-\tilde{\varepsilon}}^{1+\tilde{\varepsilon}} \int_{1-\tilde{y}}^{1} d_{1 d} \varepsilon_{1 d} \\
& \left(0.9 P_{1 d} y_{1 d}-7.65 y_{1 d}-0.5\right) f\left(y_{1 d}\right) f\left(\varepsilon_{1 d}\right) d y_{1 d} d \varepsilon_{1 d} \\
& +\int_{1-\tilde{\varepsilon}}^{1+\tilde{\varepsilon}} \int_{1}^{1+\tilde{y}} d_{1 d} \varepsilon_{1 d}\left(0.9 P_{1 d}-6.65-1.5 y_{1 d}\right) \\
& f\left(y_{1 d}\right) f\left(\varepsilon_{1 d}\right) d y_{1 d} d \varepsilon_{1 d} .
\end{aligned}
$$

The profit gained by manufacturer 2 via an internet- 
based sales channel might be derived using Eq. (59):

$$
\begin{aligned}
\pi_{2(I)}= & \int_{1-\tilde{\varepsilon}}^{1+\tilde{\varepsilon}} \int_{1-\tilde{y}}^{1} d_{2 d} \varepsilon_{2 d}\left(0.9 P_{2 d} y_{2 d}-7.65 y_{2 d}-0.5\right) \\
& f\left(y_{2 d}\right) f\left(\varepsilon_{2 d}\right) d y_{2 d} d \varepsilon_{2 d}+\int_{1-\tilde{\varepsilon}}^{1+\tilde{\varepsilon}} \int_{1}^{1+\tilde{y}} d_{2 d} \varepsilon_{2 d} \\
& \left(0.9 P_{2 d}-6.65-1.5 y_{2 d}\right) f\left(y_{2 d}\right) f\left(\varepsilon_{2 d}\right) d y_{2 d} d \varepsilon_{2 d} .
\end{aligned}
$$

Besides, the wholesales profit of manufacturer 2 is similar to what is shown by Eq. (60):

$$
\begin{aligned}
\pi_{2(w)}= & \int_{1-\tilde{\varepsilon}}^{1+\tilde{\varepsilon}} \int_{1-\tilde{y}}^{1} 7 d_{2 r} \varepsilon_{2 r} y_{2 r} f\left(y_{2 r}\right) f\left(\varepsilon_{2 r}\right) d y_{2 r} d \varepsilon_{2 r} \\
& +\int_{1-\tilde{\varepsilon}}^{1+\tilde{\varepsilon}} \int_{1}^{1+\tilde{y}} d_{2 r} \varepsilon_{2 r}\left(47.5+2 y_{2 r}\right) f\left(y_{2 r}\right) \\
& f\left(\varepsilon_{2 r}\right) d y_{2 r} d \varepsilon_{2 r} .
\end{aligned}
$$

Hence, the total profit of manufacturer 2 is defined by Eq. (61):

$$
\begin{aligned}
\pi_{2}= & \pi_{2(w)}+\pi_{2(I)}=\int_{1-\tilde{\varepsilon}}^{1+\tilde{\varepsilon}} \int_{1-\tilde{y}}^{1} 7 d_{2 r} \varepsilon_{2 r} y_{2 r} f\left(y_{2 r}\right) \\
& f\left(\varepsilon_{2 r}\right) d y_{2 r} d \varepsilon_{2 r}+\int_{1-\tilde{\varepsilon}}^{1+\tilde{\varepsilon}} \int_{1}^{1+\tilde{y}} 7 d_{2 r} \varepsilon_{2 r} \\
& \left(47.5+2 y_{2 r}\right) f\left(y_{2 r}\right) f\left(\varepsilon_{2 r}\right) d y_{2 r} d \varepsilon_{2 r} \\
& +\int_{1-\tilde{\varepsilon}}^{1+\tilde{\varepsilon}} \int_{1-\tilde{y}}^{1} d_{2 d} \varepsilon_{2 d}\left(0.9 P_{2 d} y_{2 d}-7.65 y_{2 d}-0.5\right) \\
& f\left(y_{2 d}\right) f\left(\varepsilon_{2 d}\right) d y_{2 d} d \varepsilon_{2 d}+\int_{1-\tilde{\varepsilon}}^{1+\tilde{\varepsilon}} \int_{1}^{1+\tilde{y}} d_{2 d} \varepsilon_{2 d} \\
& \left(0.9 P_{2 d}-6.65-1.5 y_{2 d}\right) f\left(y_{2 d}\right) f\left(\varepsilon_{2 d}\right) d y_{2 d} d \varepsilon_{2 d} .
\end{aligned}
$$

The profit of a repair center obtained from the internetbased sales of second-hand products might be calculated using Eq. (62):

$$
\begin{aligned}
\pi_{r p(I)}= & \int_{1-\tilde{\varepsilon}}^{1+\tilde{\varepsilon}} \int_{1-\tilde{y}}^{1} d_{r p d} \varepsilon_{r p d}\left(0.9 P_{r p d} y_{r p d}-4.76 y_{r p d}\right. \\
& -0.4) f\left(y_{r p d}\right) f\left(\varepsilon_{r p d}\right) d y_{r p d} d \varepsilon_{r p d} \\
& +\int_{1-\tilde{\varepsilon}}^{1+\tilde{\varepsilon}} \int_{1}^{1+\tilde{y}} d_{r p d} \varepsilon_{r p d}\left(0.9 P_{r p d}-2.24\right. \\
& \left.-2.6 y_{r p d}\right) f\left(y_{r p d}\right) f\left(\varepsilon_{r p d}\right) d y_{r p d} d \varepsilon_{r p d} .
\end{aligned}
$$

Furthermore, a repair center makes profit through wholesale of its second-hand products. This is shown by Eq. (63):

$$
\begin{aligned}
\pi_{r p(w)}= & \int_{1-\tilde{\varepsilon}}^{1+\tilde{\varepsilon}} \int_{1-\tilde{y}}^{1} 5 d_{r p r} \varepsilon_{r p r} y_{r p r} f\left(y_{r p r}\right) \\
& f\left(\varepsilon_{r p r}\right) d y_{r p r} d \varepsilon_{r p r}+\int_{1-\tilde{\varepsilon}}^{1+\tilde{\varepsilon}} \int_{1}^{1+\tilde{y}} d_{r p r} \varepsilon_{r p r} \\
& \left(7.5-2.5 y_{r p r}\right) f\left(y_{r p r}\right) f\left(\varepsilon_{r p r}\right) d y_{r p r} d \varepsilon_{r p r}
\end{aligned}
$$

The total profit function of a repair center is defined by Eq. (64):

$$
\begin{aligned}
\pi_{r p}= & \int_{1-\tilde{\varepsilon}}^{1+\tilde{\varepsilon}} \int_{1-\tilde{y}}^{1} d_{r p d} \varepsilon_{r p d}\left(0.9 P_{r p d} y_{r p d}-4.76 y_{r p d}\right. \\
& -0.4) f\left(y_{r p d}\right) f\left(\varepsilon_{r p d}\right) d y_{r p d} d \varepsilon_{r p d} \\
& +\int_{1-\tilde{\varepsilon}}^{1+\tilde{\varepsilon}} \int_{1}^{1+\tilde{y}} d_{r p d} \varepsilon_{r p d}\left(0.9 P_{r p d}-2.24\right. \\
& \left.+2.6 y_{r p d}\right) f\left(y_{r p d}\right) f\left(\varepsilon_{r p d}\right) d y_{r p d} d \varepsilon_{r p d} \\
& +\int_{1-\tilde{\varepsilon}}^{1+\tilde{\varepsilon}} \int_{1-\tilde{y}}^{1} 5 d_{r p r} \varepsilon_{r p r} y_{r p r} f\left(y_{r p r}\right) f\left(\varepsilon_{r p r}\right) \\
& d y_{r p r} d \varepsilon_{r p r}+\int_{1-\tilde{\varepsilon}}^{1+\tilde{\varepsilon}} \int_{1}^{1+\tilde{y}} d_{r p r} \varepsilon_{r p r}(7.5 \\
& \left.-2.5 y_{r p r}\right) f\left(y_{r p r}\right) f\left(\varepsilon_{r p r}\right) d y_{r p r} d \varepsilon_{r p r},
\end{aligned}
$$

$\varepsilon$ and $y$ random variables have uniform distribution over $[1-\bar{\varepsilon}, 1+\bar{\varepsilon}]$ and $[1-\bar{y}, 1+\bar{y}]$ where $\bar{\varepsilon}$ and $\bar{y}$ are determined based on $c v_{y}=0.35$ and $c v_{x}=0.2$ coefficients of variations.

First of all, the existence and uniqueness of solution were examined for the numerical example. Then, models were solved through the three mentioned scenarios. The results of calculations are summarized in Table 1 (to solve the problem, MATLAB coding is exploited to overcome complexity and heavy computational load).

\section{Analyzing the impact of parameters on profit and order}

To facilitate the analysis of the proposed model, some diagrams are provided in this section. These illustrate how variations in some parameters affect different profit functions.

Figure 2 depicts the effect of variations in several parameters such as $b_{1 r}$ and $b_{1 d}$ (product price selfsensitivity parameter in retailer's and internet-based 
Table 1. Optimal values for price of products in different channels, order values, and the profit of players (manufacturer, repair center, and retailer) in different strategies.

\begin{tabular}{|c|c|c|c|c|c|c|c|c|c|c|c|}
\hline Scenarios & $\boldsymbol{P}_{1 d}\left(\boldsymbol{P}_{\mathbf{2 d}}\right)$ & $\boldsymbol{P}_{\text {rpd }}$ & $\boldsymbol{P}_{1 r}\left(\boldsymbol{P}_{2 r}\right)$ & $\boldsymbol{P}_{\boldsymbol{r p r}}$ & $q_{1 d}\left(q_{2 d}\right)$ & $q_{1 r}\left(q_{2 r}\right)$ & $q_{r p d}$ & $q_{r p r}$ & $\boldsymbol{\pi}_{1}\left(\boldsymbol{\pi}_{2}\right)$ & $\pi_{R}$ & $\pi_{r p}$ \\
\hline Nash game structure & 16 & 11 & 18 & 16 & 133 & 96 & 122 & 82 & 193 & 42 & 91 \\
\hline $\begin{array}{l}\text { Stackelberg game with manufacturer } \\
\text { and repair center as leaders } \\
\text { (first scenario) }\end{array}$ & 15 & 10 & 18 & 16 & 140 & 96 & 129 & 71 & 186 & 81.5 & 45 \\
\hline $\begin{array}{c}\text { Stackelberg game with retailer as } \\
\text { leaders (second scenario) }\end{array}$ & 15 & 10 & 18 & 16 & 140 & 96 & 129 & 71 & 186 & 81.5 & 45 \\
\hline
\end{tabular}

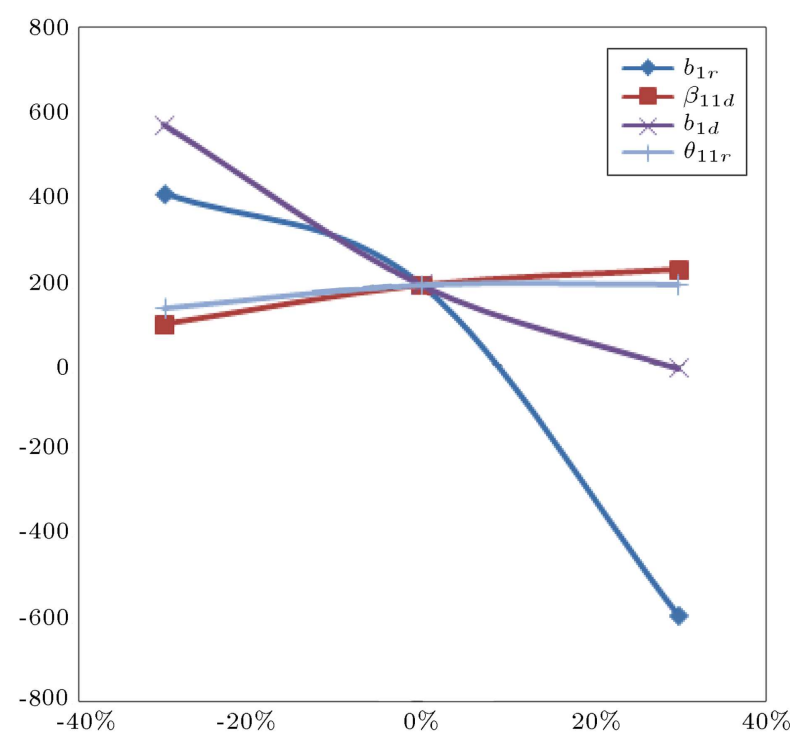

Figure 2. Investigating how self-sensitivity and inter channel sensitivity of product 1 affect the profit of manufacturer 1 in Nash game.

channels, respectively) and sensitivity to price of product 1 sold in different channels ( $\beta_{11 d}$ : inter-channel sensitivity of product 1 demand in a retailer's channel to the price of product 1 in an internet-based channel; $\theta_{11 r}$ : inter-channel sensitivity of product 1 demand in an internet-based channel to the price of product 1 in a retailer's channel). The investigated structure in this figure is Nash game.

As is obvious from Figure 2, self-sensitivity parameters adversely affect profitability. They may even lead to negative profitability in case of an excessive increase. Therefore, sensitivity of customer to price must be reduced. This goal can be achieved by increasing customers' loyalty. Better services, improved accessibility, simple purchasing methods, and modified advertisement might be leveraged to increase customers' loyalty. Moreover, sensitivity of product 1 price in a retailer's channel to its demand in an internet-based channel positively affects profit. It means that profit can be increased via boosting customers' loyalty to a specific channel. In contrast,

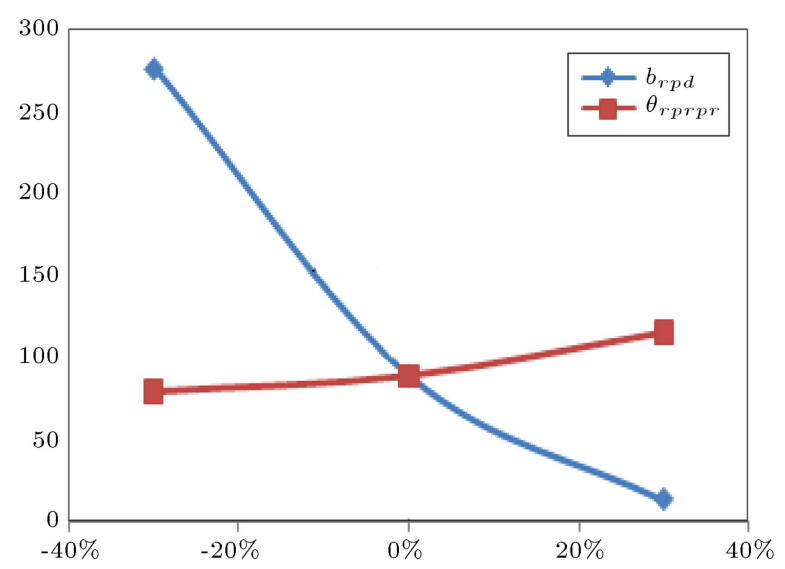

Figure 3. The effect of changes in some parameters on a repair center's profit.

sensitivity of profit function to $\beta_{11 d}$ and $\theta_{11 r}$ is much less than its sensitivity to $b_{1 r}$ and $b_{1 d}$ parameters. Therefore, it is concluded that increasing customer's loyalty to the product is more beneficial than increasing customer's loyalty to the sales channel.

Figure 3 illustrates how variations in $\theta_{\text {rprpr }}$ (the sensitivity of second-hand product demand in an internet-based channel to its price in retailer channel) and $b_{r p d}$ (the self-sensitivity of second-hand product price in an internet-based channel) affect the profit of a repair center in Nash game.

Similar to Figure 2, Figure 3 reveals that selfsensitivity of the second-hand product negatively affects the profit while its inter-channel sensitivity positively impacts the repair center profit.

Figure 4 shows the effect of price sensitivity parameters in a Stackelberg structure.

The same conclusions might be derived when parameters are analyzed in Stackelberg game conditions. Figure 4 shows that an increase in self-sensitivity parameters even may lead to negative profitability.

Figure 5 demonstrates how the service level of product 2 affects the second manufacturer's profit.

As can be seen in Figure 5, increasing the service level firstly increases profitability; however, if it exceeds a specific bound, it decreases profit as it raises cost 


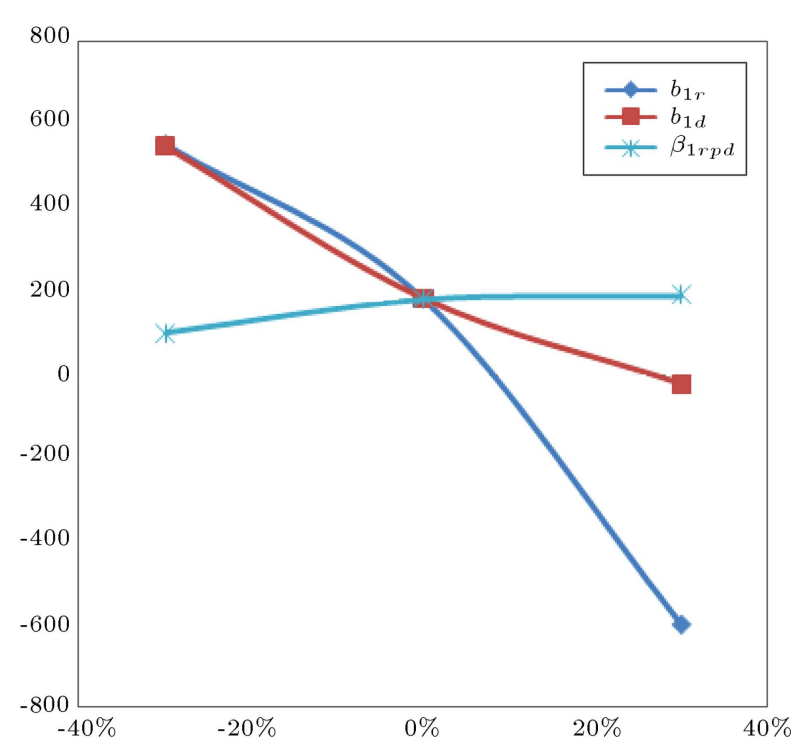

Figure 4. The effect of changes in self-sensitivity and inter-channel parameters of product 1 on the first manufacturer's profit in Stackelberg game.

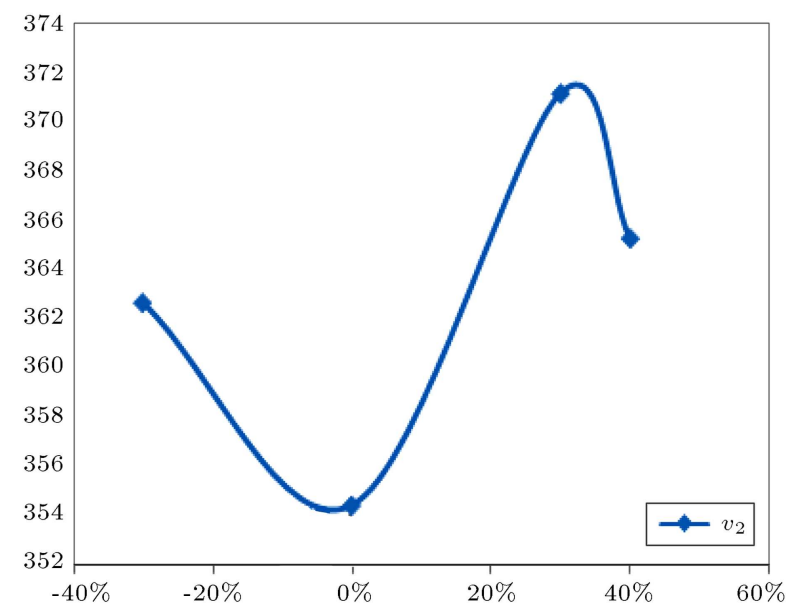

Figure 5. The effect of changes in service level of product 2 on manufacturer's profit in Stackelberg game.

price of the product which, in turn, reduces product desirability for customers. On the other hand, decreasing the service level reduces cost price considerably. Thus, it increases product desirability for customers. Optimal values for service level are derived via solving profit equations in terms of the optimal service level.

\section{Conclusion}

This paper investigated the inventory and pricing problem in a closed-loop supply chain with a few manufacturers and a repair center. Manufacturers generate substitutable products. The repair center collects the products used by customers, repairs them, and sells them as second-hand products at a lower price. Furthermore, customers may return products before use. The returned products are sold again. In the assumed supply chain, manufacturers and repair centers sell their products using a common retailer channel. Besides, they have their own internet-based sales channel. This supply chain model was solved using three different strategies in a decentralized manner. The exploited strategies include Nash game, Stackelnberg structure with a manufacturer, a repair center as leaders, and Stackelberg structure with a retailer as the leader. The constraints regarding the existence and uniqueness of solution were also examined. To achieve a better insight, a numerical example was provided which considered identical products. The results demonstrated the importance of competition between sales channels and products. Nevertheless, results revealed that the effect of inter-brand competition is more crucial than that of inter-channel competitions are. Therefore, players should increase customers' loyalty (and in turn their profitability) using different policies such as increasing service level, better advertisement, and obtaining competitive superiorities.

According to our study, the following topics sound interesting for further research:

- Considering internet-based sales channel for a common retailer;

- Considering several retailers for a supply chain;

- Determining an optimal location of a repair center through solving the location problem.

\section{References}

1. Gan, S.-S., et al. "Pricing decision for new and remanufactured product in a closed-loop supply chain with separate sales-channel", International Journal of Production Economics, 190, pp. 120-132 (2017).

2. Chiang, W.K., Chhajed, D., and Hess, J. "Direct marketing, indirect revenues: A strategic analysis of dual-channel supply chain design", Management Science, 49, pp. 1-20 (2003).

3. Kumar, N. and Ruan, R. "On manufacturers complementing the traditional retail channel with a direct online channel", Quantitative Marketing and Economics, 4, pp. 289-323 (2006).

4. Dai, Y., Chao, X., Fang, S., and Nuttle, H.L.W. "Pricing in revenue management for multiple firms competing for customers", International Journal of Production Economics, 98, pp. 1-16 (2005).

5. Kurata, H., Yao, D.Q., and Liu, J.J. "Pricing policies under direct vs. indirect channel competition and national vs. store brand competition", European Journal of Operational Research, 180, pp. 262-281 (2007). 
6. Hsieh, C.-C., Chang, Y.-L., and Wu, C.-H. "Competitive pricing and ordering decisions in a multiplechannel supply chain", International Journal of Production Economics, 154, pp. 156-165 (2014).

7. Georgiadis, P. and Besiou, M. "Environmental and economical sustainability of WEEE closed loop supply chains with recycling: A system dynamics analysis Technology", International Journal of Advanced Manufacturing, 47, pp. 475-493 (2010).

8. Huang, M., Song, M., Lee, L.H., and Ching, W.K. "Analysis for strategy of closed-loop supply chain with dual recycling channel", Int. J. Production Economics, 144, pp. 510-520 (2013).

9. Maiti, T. and Giri, B.C. "A closed loop supply chain under retail price and product quality dependent demand", Journal of Manufacturing Systems, 37, Part 3, pp. 624-637 (2015).

10. Ramezani, M., Kimiagari, A.M., and Karimi, B. "Closed-loop supply chain network design: A financial approach", Applied Mathematical Modelling, 38, pp. 4099-4119 (2014).

11. Kaya, O. and Urek, B. "A mixed integer nonlinear programming model and heuristic solutions for location, inventory and pricing decisions in a closed loop supply chain", Computers \& Operations Research, 65, pp. 93-103 (2016). http://dx.doi.org/10.1016/j.cor.2015.07.005

12. Dan, B., Xu, G., and Liu, C. "Pricing policies in a dual-channel supply chain with retail services", Int. J. Production Economics, 139, pp. 312-320 (2012).

13. Chen, Y., Fang, S., and Wena, U. "Pricing policies for substitutable products in a supply chain with Internet and traditional channels", European Journal of Operational Research, 224, pp. 542-551 (2013).

14. Zhao, J., Liu, W., and Wei, J. "Competition under manufacturer service and price in fuzzy environments", Knowledge-Based Systems, 50, pp. 121-133 (2013).

15. Xiao, T. and $\mathrm{Xu}, \mathrm{T}$. "Coordinating price and service level decisions for a supply chain with deteriorating item under vendor managed inventory", Int. J. Production Economics, 145, pp. 743-752 (2013).

16. Zhao, J., Wei, J., and Li, Y. "Pricing decisions for substitutable products in a two-echelon supply chain with firms' different channel powers", Int. J. Production Economics, 153, pp. 243-252 (2014).

17. Zhao, J. and Wang, L. "Pricing and retail service decisions in fuzzy uncertainty environments", $A p$ plied Mathematics and Computation, 250, pp. 580-592 (2015).

18. Maiti, B.C. and Giri, B.C. "Two-period pricing and decision strategies in a two-echelon supply chain underprice-dependent demand", Applied Mathematical Modelling, 24, pp. 655-674 (2017). DOI: 10.1016/j.apm.2016.10.051

19. Zhou, L., Naim, M.M., and Disney, S.M. "The impact of product returns and remanufacturing uncertainties on the dynamic performance of a multi-echelon closedloop supply chain", International Journal of Production Economics, 183, Part B, pp. 487-502 (2017).

20. Seung, H.Y. and Byung, Ch.K. "Joint pricing of new and refurbished items: A comparison of closedloop supply chain models", International Journal of Production Economics Volume, 182, December, pp. 132-143 (2016).

21. Chen, B. and Chen, J. "When to introduce an online channel, and offer money back guarantees and personalized pricing?", European Journal of Operational Research Volume, 257(2), 1 March, pp. 614-624 (2017).

22. Topkis, D.M. "Equilibrium points in nonzero-sum nperson submodular games", SIAM Journal on Control and Optimization, 17, pp. 773-787 (1979).

23. Topkis, D.M., Supermodularity and Complementarity, Princeton University Press, New Jersey (1998).

24. Milgrom, P. and Roberts, J. "Rationalizability, learning, and equilibrium in games with strategic complementarities", Econometrica, 58, pp. 1255-1277 (1990).

25. Matsumoto, T. and Shimemura, E. "The Kuhn-Tucker conditions and multistage games", Journal of Mathematical Analysis and Applications, 23, pp. 269-283 (1968).

26. Leyffer, S. and Munson, T. "Solving multi-leaderfollower games", Mathematics and Computer Science Division Argonne National Laboratory, Argonne, IL 60439, USA, April (2005).

27. Stankova, K. "On Stackelberg and inverse Stackelberg games \& their applications in the optimal toll design problem, the energy markets liberalization problem, and in the theory of incentives", NGInfra PhD Thesis Series on Infrastructures No. 22, ISBN 978-90-7978703-6 (2009).

28. Hsieh, C.C. and Wu, C.H. "Coordinated decisions for substitutable products in a common retailer supply chain", European Journal of Operational Research, 196, pp. 273-288 (2009).

29. Cachon, G.P. and Netessine, S. "Game theory in supply chain analysis", In Handbook of Quantitative Supply Chain, Boston: Kluwer Academic Publishers, pp. 13-65 (2004).

\section{Biographies}

Leila Nazari received her BSc degree in Industrial Engineering in 2001 from the Alzahra University, Tehran, Iran and also obtained her MSc degree in Industrial Engineering in 2003 from K. N. Toosi University of Technology, Tehran, Iran. She obtained her PhD degree in Industrial Engineering in 2015 from Science 
and Research branch, Islamic Azad University, Tehran, Iran. She is an Assistant Professor at the Department of Industrial Engineering, Abhar Branch, Islamic Azad University, Abhar, Iran. Her research interests include supply chain management, inventory control, and MCDM.

Mehdi Seifbarghy received his BSc degree in Industrial Engineering in 1998 from Sharif University of Technology, Tehran, Iran and his MSc degree in Industrial Engineering in 2000 from Sharif University of Technology, Tehran, Iran. He also received his $\mathrm{PhD}$ degree in Industrial Engineering in 2005 from Sharif University of Technology, Tehran, Iran. He is an Associate Professor at the Department of Industrial
Engineering, Alzahra University. His research interests include supply chain management and facility location.

Mostafa Setak received his BSc degree in Industrial Engineering from Sharif University of Technology, Tehran, Iran and his MSc degree in Industrial Engineering from University of Science and Technology, Tehran, Iran. He also obtained his $\mathrm{PhD}$ degree in Industrial Engineering from Tarbiat Modares University, Tehran, Iran. $\mathrm{He}$ is an Associate Professor at the Department of Industrial Engineering, K.N. Toosi University of Technology. His research interests include routing problem, inventory control, supply chain management, and strategic management. 